\title{
Gender Differentials in Migration Impacts in Southern Ethiopia
}

\author{
Nigatu Regassa and Ansha Yusufe \\ Hawassa University, Department of Rural Development and Family Sciences, P.O.Box 679, \\ Awassa, SNNPR, Ethiopia \\ Telephone: 251-46-2206698,E-mail: negyon@yahoo.com
}

KEYWORDS Gender. Differentials. Southern Ethiopia. Zones. Woredas. Kebeles

\begin{abstract}
The Southern Nations, Nationalities Peoples Region (SNNPR) of Ethiopian is experiencing one of the highest population growth rate (about 2.8 percent per annum) mainly as a result of very high fertility rate (Total Fertility Rate, TFR, of 5.9). Like in other parts of the country, rural-urban migration is an increasingly becoming common phenomenon mainly as direct response to environmental degradation and rural poverty. While there are interwoven socio-economic and ecological factors contribute to the migration of influx of people into the increasingly important medium sized urban areas of the region, the migration impacts on the migrants at destination (urban centers) is less researched, and hence, worth investigating. This article thus tries to examine the gender differentials of migration impacts at the place of destinations by taking the experiences of four major urban areas of the Southern Region (Awassa town, Wolkite town, Durame, and Soddo). The study is based on primary data collected from 821 urban migrants selected from four of the most populous districts (zone) of southern Ethiopia namely Sidama, Wolayita, Kembata Tembaro and Guraghe zones. The study has employed Chi-square analysis to examine the possible gender differentials of migration impacts at the place of destination. The study employed both the quantitative and qualitative approaches in the course of collecting and analyzing the data. The study has documented that there are certain gender differentials in the impacts of migration at the place of destination: Male migrants are more prone to some of the socio-economic problems (such as unemployment) than their counterpart female migrants. Similarly, female migrants are found to be more prone to some of urban problems (such as, lack of food, lack of adequate health service, homesickness, labor and sexual abuses and the like) than their counterpart male migrants.
\end{abstract}

\section{INTRODUCTION}

With an estimated population of about 77 million, Ethiopia is the second most populous country of Africa, next to Nigeria. Fuelled by a high level of fertility rate, the country is experiencing high annual population growth rate of about 2.6 percent. The population is estimated to increase over the decades from 42.6 million in 1984 to 77 million in 2005.

Ethiopia is an agrarian country where agriculture accounts for more than sixty percent of the GDP, employing about 85 percent of the population, and accounts for about 90 percent of the export (CSA, 2000). The country had continues environmental degradation and agricultural production failure which is a major constraint in making up a sustainable livelihood for many Ethiopian poor in rural areas. In addition to environmental problems, farmers face numerous constraints related to small and diminishing farm sizes, low tenure security, imperfect agricultural markets that together brought about an average decline of per capita agricultural production by 0.64 percent over the last ten years (ECA 2001). The country is one of the least developed in the world, with a per capita Gross National Product (GNP) in year 2004 of US \$ 98 As one of the indicators of economic status of the population, the household expenditure shows very unpleasant distribution.

Among the nine federal states of the country, the Southern Nations, Nationalities and Peoples Region (SNNPR), which is the concern of this study, is located in the southern part of the country. With an area of 113,539 square kilometers, it accounts for about 10 percent of the total area of the country. The region is constitute of twelve sub-regional administrative areas called 'Zones' classified on the basis of ethnicity (Sidama, Gurage, Hadya, Wolaita, Bench Maji, Semen Omo, Debub Omo, Gedeo, Keficho, Kembatta, Alaba Tembaro, and Silti). In the year 2004, the population of the region was estimated at about 14 million, giving a male to female sex ratio of 98.8. The region's population accounts for 20 percent of the total population of the country, which makes it the third populous region in the country next to Oromia and Amhara federal states (SNNPRG 2001; CSA 2000).

The population profile of the region is characterized by large number of children under 15 
(46.7 percent) while those in the age group 15-64 and above 64 accounts for 50 and 3.3 percent respectively. The median age of the population in the year 2001 was estimated to be about 17 years. Out of the total population of the region, women in the reproductive age (15-49) account for about 3,346,993 in the year 2004. According to a recent estimate, about 8 percent of the total population of the region is residing in urban areas while the bulk of the population (92 percent) are living in rural areas. The overall life expectancy at birth is about 52.4 years ( 51.35 for males and 53.45 for females) while the other two most sensitive indicators, infant and child mortality rates, are 107 deaths per 1000 births and 157 deaths per 1000 children under five respectively. About 43.2 percent of the population is estimated to be economically active

The region is one of those with uneven distribution of population with crude density of 123 persons per square kilometer in the year 1995 E.C .The net density of the region is about 448 persons per cultivated land (per hectare). It is reported that the highlands of Gamogofa, Wolaita, Sidama, Hadya, Guraghe and KAT zones constitute about 45 percent of the population of the region (SNNPR 2001). Within these zones, population density ranges between 400 and 600 persons per square kilometer. On the other hand, the sparsely populated areas of the region accounts for about 56 percent of the total area with a population density of 3 to 10 persons, 2.5 percent of the population of the region (SNNPRG 2001). Residential pattern of the region's population distribution show that 8.3 percent of the population is living in urban areas while the bulk of the population $(91.7 \%)$ is residing in rural areas. About 43.2 percent of the population is estimated to be economically active. The crude birth rates and Total Fertility Rate of the region in recent years was 42.6 and 5.9 respectively (CSA 2000) The region is experiencing one of the highest Infant Mortality Rate (113.4 per 1000 live births), under five mortality of 192 for both sexes and maternal mortality rate of above 850 per 100,000 live births (CSA 2000).

Poverty is one of the most important concerns of the region where about 56.8 percent of the total population is living under poverty line. It is estimated that about 46.2 percent of the farmers in the region own 0.1-0.5 hectare of land per household whereas the proportion who have land size of more than 2 hectare per household are only 4.7 percent. About 53.9 percent of children are stunted, 12 percent are severely wasted and 52.5 percent are under weight (CSA 2000)... On top of these, the region exhibits one of the lowest health service coverage (46.\%) in the country (SNNPRG 2001). Lack of good antenatal delivery, poor postpartum care, malnutrition, anemia, high fertility and the like contributed to the high regional maternal mortality rate. Moreover, sexually transmitted diseases are among the major health concern of the region.

Like other parts of the country, movement of people across regional and zonal boundaries is historically a common phenomenon where influx of people migrates to small and big towns due to economic and other non-economic reasons. The phenomenon of migration carries several economic, social, and cultural problems in the region. A short visit in the different parts of the region shows that migration is becoming serious problems of most small and growing urban areas.

In Ethiopia, including the Southern region, massive movement of people from place to place have been caused by both natural and man-made disasters. Earlier researches witnessed that landlessness, agricultural policy, land fragmentation, environmental degradation, population pressure, recurrent drought and famine, war and political crises were the major factors responsible for spatial mobility (Mesfin 1986; Berhanu and White 1999). Keeping in mind the pros and cons of migratory movement of people within the country's territory, it is important to note that the process of migration (especially the gender differentials of migration impacts) should be adequately dealt with and researched. During the last few years, social scientists have devoted a great deal of attention to the theoretical and empirical importance of the timing and sequence of events in the life course of individuals and families, particularly in relation to migration (Murphy 1996; Ezra 2001).

Migration seems to have a generally empowering impact on women themselves in terms of higher self-esteem and increased economic independence both as family members and as economic actors. While migration provides productive labour and an economic lifeline for millions of women, the plight of unprotected female migrant workers has become an increasing source of public concern as evidence of abuses mounts. 
It has become clear that migrants, most of whom come with low level of skills and education, are prone to a number of social crisis at the place of destination such as being victims of unemployment, homelessness, lack good access to health and other social services. Among others, women migrants are known to face multiple problems at the place of destination including sexual harassment, labor exploitation and all forms of physical abuses. However, the notion of migration should not only be seen from the view points of its negative implications as it is also seen to play positive role in socio-economic development of a nation or region. The outflow of migrants, for instance, manifests itself in the changing labor marked scenario in the rural economy which losses the more productive members of its labour force to the urban economy. When people, particularly women, migrate with strong economic motives to the different urban areas of a region/country, they will undergo dramatic attitudinal changes, which in turn bring about increased empowerment and family transformation.

This is an empirical study aiming at examining the gender differentials of the impact of migration in selected administrative zones of Southern Nations Nationalities Peoples Regional State (SNNPRS), namely Sidama, Wolaita, KembattaTembaro and Gurage zones or sub-regions.

\section{DATA AND METHOD}

Data Source: The prime data for this study was generated from primary sources through the use of questionnaire. In order to augment the quantitative data, the study has made use of the qualitative information collected through Focus Group Discussion. The full data collection expenses were borne by the Regional Office of Population with professional assistance from Hawassa University.

Sampling Design: As mentioned in section 2 above, the SNNPRS consists of about thirteen zones and eight special woredas with diversified culture, language and economic activities. To begin with, the sample size required and the procedure to be followed in any study is determined by the objective of the study, the resource available, types of the study, variability of the characteristics to be measured, the precision required, and the required confidence that the precision is valid.
The process of sampling started with the listing out of all zones where population mobility across boundaries (migration) is known to be high. As per the informal discussion with the regional office of population, it was known that four of the thirteen zones are historically more vulnerable to migration. The four zones namely Sidama, Gurage, Kambata-Tambaro and Wolaita are thus selected using one of the non-probability sampling techniques called purposive sampling. Following this, three kebeles from four major urban areas of the respective zones were selected using simple random sampling technique, giving a total of 12 kebeles. While selecting these urban kebeles, care was taken to include those kebeles where the low-income migrants are concentrated since rural migrants usually prefer to reside in areas where cheaper dwelling units and small business activities can be found. A list of households and individual migrant in the selected urban kebeles were taken from the kebele administration to randomize the selection of individuals and households. From the list of individual migrants who migrated to the place of destination during the last 10 years reference period, a total of 821 migrants (age 14 and above) were selected for interview.

Data Collection, Processing and Analysis: The required data for the study were collected for about twenty days. Following the successful completion of data collection, the data were code, entered into SPSS software, cleaned and made ready for analysis. The analysis on the Gender Differentials of migration was done using simple Chi-square statistical techniques. .

\section{RESULTSAND DISCUSSIONS}

\subsection{Background Characteristics of Respondents}

The major background characteristics of migrant are presented in table 1 . The sex distribution of the respondents shown in table 1 indicates that 56.6 percent are males and the rest 43.4 percent are females. Information on religious status of the migrants was also collected. It is seen that Protestant Christians account for about 50 percent of the migrants; Orthodox Christians are 36.2 percent; 11.0 percent Muslims and other religion groups contribute insignificant proportion of the total migrants. Table 1 also reveals the marital status distribution of migrants. The majority of the respondents are currently 
married (53.4\%) followed by single (40.8\%), while other categorized make up small fractions of the respondents.

The distribution of the respondents by education level shows that majority of the migrants $(28.3 \%)$ are in 9-12 level, followed by grade 5-8 $(26.1 \%)$, Diploma and above $(15.1 \%)$ and illiterate $(13.9 \%)$. It is presumed that majority of the migrants might have been illiterate prior to their move to the current destination, but develop a strong motive to develop their life skills through formal education of one kind or the other. In some cases, education is considered as survival strategies among migrants primarily enable them to get better employment opportunity and compete with the non-migrants of the place of destination.

It is seen that majority of the migrants $(55.8 \%)$ reported to come from households less than three members; 33 percent are from households having 4-6 members; 10.2 percent from 7-10 members and only 1.0 percent reported to come from households greater than 10 members. Table 1 also shows the ethnic background of migrants. It is seen that Wolayita migrants form the majority (26.1\%) followed by Gurage (17.2\%), Oromo $(11.8 \%)$, Kembata-Tembaro $(9.3 \%)$, Sidama $(6.6 \%)$, Hadya (1.9\%), and others $(6.5 \%)$.

As migration has more of economic motives, it is important to see the occupational distribution of migrants at the place of destination. In this regard, about 18 percent of the respondents are found to be engaged as civil servant and self-employment. If the employments are seen from the perspectives of formal-informal nexus, it is apparent to note that about 29.1 percent of the urban migrants are engaged in casual and in low income informal sectors such as shoe-shining, construction work, cart driving, housemaid and the like. Despite the fact that information on income is usually unreliable; this study has tried to document information about the average monthly income. Accordingly, about 40 percent of the respondents fall in the range 20-200 Ethiopian Birr per month (1 US dollar $=8.85$ Ethiopian Birr), while the no income category accounts for 16 percent of the respondents. Among the migrants, around 20 percent have reported to get a monthly income of 201-400 birr, while very small fractions $(4 \%)$ fall in the range between $801-1000^{+}$ birr. When the overall mean income of the migrants is computed, it yields about 307 birr per month.
Table 1: Percentage distribution of migrants by selected socio-economic characteristics $(N=821)$

\begin{tabular}{|c|c|}
\hline Characteristics & Percentage \\
\hline \multicolumn{2}{|l|}{$\operatorname{Sex}$} \\
\hline Male & 56.6 \\
\hline Female & 43.4 \\
\hline \multicolumn{2}{|l|}{ Current Age } \\
\hline $14-24$ & 35.3 \\
\hline $25-64$ & 64.0 \\
\hline $64^{+}$ & 0.7 \\
\hline \multicolumn{2}{|l|}{ Marital Status } \\
\hline Married & 53.4 \\
\hline Single & 40.8 \\
\hline Widowed & 2.6 \\
\hline Divorced & 1.9 \\
\hline Separated & 1.3 \\
\hline \multicolumn{2}{|l|}{ Religion } \\
\hline Orthodox & 1.9 \\
\hline Muslim & 11.0 \\
\hline Protestant & 49.7 \\
\hline Catholic & 2.1 \\
\hline Other & 1.0 \\
\hline \multicolumn{2}{|l|}{ Level of Education } \\
\hline Illiterate & 13.9 \\
\hline First cycle (1-4) & 16.6 \\
\hline Second cycle $(5-8)$ & 26.1 \\
\hline High school $(9-12)$ & 28.3 \\
\hline Diploma and above & 15.1 \\
\hline \multicolumn{2}{|l|}{ Household Size } \\
\hline Less than 3 members & 55.8 \\
\hline 4-6 members & 33.0 \\
\hline 7-10 members & 10.2 \\
\hline Greater than 10 members & 1.0 \\
\hline \multicolumn{2}{|l|}{ Ethnic Background } \\
\hline Wolayita & 26.1 \\
\hline Kembata-Tembaro & 9.3 \\
\hline Gurage & 17.2 \\
\hline Sidama & 6.6 \\
\hline Amhara & 16.4 \\
\hline Oromo & 11.8 \\
\hline Hadiya & 1.9 \\
\hline Others & 8.3 \\
\hline Gamo & 2.4 \\
\hline \multicolumn{2}{|l|}{ Monthly Income } \\
\hline 20-200 Birr & 39.6 \\
\hline $201-400$ & 19.9 \\
\hline $401-600$ & 10.8 \\
\hline $601-800$ & 6.3 \\
\hline $801-1000$ & 3.5 \\
\hline 1001 and above & 4.1 \\
\hline No income & 15.7 \\
\hline \multicolumn{2}{|l|}{ Occupation } \\
\hline Civil servant & 18.2 \\
\hline Daily laborers & 11.1 \\
\hline Cart driver & 4.3 \\
\hline Shoe shiner & 3.4 \\
\hline Housemaid & 4.9 \\
\hline Housewife & 10.0 \\
\hline Construction worker & 5.4 \\
\hline Self-employed & 17.7 \\
\hline Student & 12.3 \\
\hline Others & 12.7 \\
\hline
\end{tabular}




\subsection{Gender Differentials in the Impacts of Migration}

Gender refers to the set of characteristics assigned to men and women in a society, and which are acquired during the socialization process. They consist of the responsibilities, behavioural guidelines, norms and values, preferences, fears, activities, and expectations that culture assigns differently to men and women. In other words, gender defines what it means to be a man or a woman in a given culture and a given economic situation and social environment. The gender element in the migration phenomena is related to the motivation of men and women to move, to the migration process itself and to the conditions migrants find on their arrival to the destination.

Though it is very important to know the reason for migration (why people move), it is also equally important to analyze what problems migrants face just at arrival and during the course of their life at place of destination. It is apparent to note that migrants face a number of socioeconomic problems compared to non-migrants at the place of destination at least for certain period of time. During the first phase of their stay, migrants have to make all their level best to adjust themselves with the new life. Whether these migrants will stay at the destination or move to the next hierarchy depends mainly on how a migrant has been able to adjust himself with the multi-dimensional stock of problems and challenges. In this regard, both rural and urban migrants were asked to report problems, successes/impacts of migration of a family member. In order to make the findings more palatable and sounding, analysis was done from gender perspectives. It should be noted at this juncture that migration is documented to exert differential impacts (positive or negative) on males and females.

In recent times, female migration has been the focus of growing attention among social scientists and policy makers. More women are migrating independently to be employed in urban areas. The growing patterns is that women workers often migrate alone as single persons, unaccompanied by family members, rather than as dependent of their husbands which was previously the case. Pending the reason why women migrate to urban areas, they are more exposed to forced labor and sexual exploitation than men, also more likely to accept precarious working conditions and poorly paid job. Moreover, female migrants than men are more vulnerable to human rights abuses since they work in gender segregated and unregulated sectors of the economy such as domestic work, entertainment and sex industry. All these give gender dimension to the study of impact of migration. As part of the general neglect of the gender dimension in migration research, there remains only limited knowledge of the conditions under which and how migration process can bring differential impacts. In this section, attempt is made to examine the differential impacts of migration (gender perspectives) in the study areas.

Table 2 starts with presentation of the gender differentials of migration by reported financial problems encountered during arrival. Accordingly, 72.7 percent of males and 65.4 percent of female were reported to have encountered series of financial problems just at the beginning of their stay at the place destination. Taking all respondents together, 69.5 percent of them were reported to have faced serious financial problems. The P-value of the Chi-square analysis also revealed that there is strong association between gender and financial problems faced $(\mathrm{P}=0.018)$.

Whether the migrant faced cultural differences (cultural shocks) or not at the time of first arrival was also examined in table 2 . It is seen that only 17.2 percent of males and 24.7 percent of females reported to encounter these problems. The result of Chi-square analysis has witnessed the gender differentials of culture shock (P-value of 0.015), indicating that females are more prone to these shocks than their counterpart females.

Becoming unemployed is quite a common phenomena for majority of migrants. Table 2 reveals that 55.7 percent of males and 57.6 percent of males were reported to have faced unemployment problem for some times at the first stage of their arrival at the place of destination. The results of the Chi-square rather revealed no significant association between the two variables i.e. both males and females have equally faced unemployment problem at the beginning of their arrival at the place of destination.

Some migrants face long working hour compared to the non-migrants, which is also conceived as a means of survival strategies. In this regard, respondents were asked to report if they had faced long working hours. Accordingly, only 29.7 percent of males and 28.7 percent females 
Table 2 Chi-square analysis of reported problems and perceived success encountered by the migrants at the place of destination

\begin{tabular}{|c|c|c|c|c|}
\hline \multirow[t]{2}{*}{ Variables } & \multicolumn{2}{|c|}{$\operatorname{Sex}$} & \multirow[t]{2}{*}{ Total } & \multirow{2}{*}{$\begin{array}{l}P \text { value of } \\
\text { chi-square }\end{array}$} \\
\hline & Male & Female & & \\
\hline \multicolumn{5}{|l|}{ Problems Encountered Upon Arrival } \\
\hline Financial problem & 72.7 & 65.4 & 69.5 & $0.018 *$ \\
\hline Cultural difference & 17.2 & 24.7 & 20.7 & $0.015 *$ \\
\hline Unemployment & 55.7 & 57.6 & 56.5 & 0.415 \\
\hline Working long hours & 29.7 & 28.7 & 29.2 & 0.435 \\
\hline Inappropriate housing facility & 78.1 & 73.6 & 76.1 & 0.128 \\
\hline Homesickness & 61.5 & 75.3 & 67.5 & $0.000 * * *$ \\
\hline Health problem & 19.8 & 29.5 & 24.0 & $0.003 * *$ \\
\hline Climatic condition & 15.3 & 22.5 & 18.4 & $0.015^{*}$ \\
\hline \multicolumn{5}{|l|}{ Problems in the Course of Stay } \\
\hline Unemployment & 54.8 & 55.3 & 55.1 & 0.463 \\
\hline Susceptibility to disease & 21.4 & 27.2 & 23.9 & $0.069 *$ \\
\hline Labour exploitation & 28.0 & 25.3 & 26.8 & 0.311 \\
\hline Loosen family ties & 58.3 & 58.7 & 58.5 & 0.464 \\
\hline Lack of food & 42.8 & 31.5 & 37.9 & $0.002 * *$ \\
\hline Sexual harassment & 4.7 & 18.0 & 10.5 & $0.000 * * *$ \\
\hline Vulnerability to crime & 12.0 & 11.5 & 11.8 & 0.449 \\
\hline Homelessness & 57.4 & 53.1 & 55.5 & 0.197 \\
\hline Unequal opportunity every aspect of life & 40.9 & 45.8 & 43.0 & 0.184 \\
\hline Vulnerability to Social crises & 5.2 & 12.1 & 8.2 & $0.001 * *$ \\
\hline \multicolumn{5}{|l|}{ Perceived Success of Migration } \\
\hline Better income opportunity & 60.0 & 43.0 & 52.6 & $0.000 * * *$ \\
\hline Better education opportunity & 57.2 & 52.8 & 53.3 & 0.439 \\
\hline Better job opportunity & 58.1 & 40.4 & 50.4 & $0.000 * * *$ \\
\hline Better health facilities & 60.0 & 57.6 & 59.0 & 0.766 \\
\hline Better status of women & 36.8 & 54.5 & 44.5 & $0.000 * * *$ \\
\hline Improvement in coping mechanisms skill of migration & 82.6 & 84.0 & 83.2 & 0.865 \\
\hline
\end{tabular}

are reported to have undergone long working hour during the first course of their stay at the place of destination. The Chi-square values (Pvalue of 0.435 ) revealed no association between the two variables.

Respondents were also asked to report the type of housing facilities they had just at the time of arrival at the place of destination. It is revealed in table 2 that 78.1 percent of males and 73.6 percent of the females have reported to face serious housing problems at the beginning of their stay at the place of destination. The Chisquare result revealed insignificant association between the two variables ( $\mathrm{P}$ value of 0.128 ).

The sex differentials of migrants by reported health problems encountered is revealed in table 2. It is evident from the table that 19.8 percent of males and 29.5 percent of female reported to have encountered health problems of one kind or the other at the time of first arrival at the current destination. The results of the Chi-Square have also witnessed strong relationship between sex and reported health problems faced (P-value of 0.003).

Even though the weather condition (climatic change) seems to exert similar pressure on the adaptability of both male and female migrants, the perception of the two groups differ. Table 2 shows that only 15.3 percent of males and 22.5 percent of the female respondents reported to have faced this problem at first arrival. Overall, only 18.4 percent of the respondents reported to have faced the problem. The Chi-square analysis also witnessed significant association between the two variables (P-value of 0.015 ).

Specific gender-related issues become evident when, for example, female migrants suffer human abuses and violations by those who take advantage of their dual vulnerability as migrants and women. Such abuses occur even in the first phase of migration, during transit, and when they enter the destinations. During the travel these abuses can include: demand of higher payments, greater exposure to robbery, intimidation, fre- 
quent sexual harassment, and violation of their physical integrity (and that of their daughters and grand-daughters) from smugglers and by male compatriots accompanying them on the trip. In addition, on arrival, gender becomes a factor that increases the female migrants' vulnerability with respect not only of women's insertion into the labour market and the society of the receiving country, but also in her economic development during her stay. Studies indicate that migrants usually face problems during the course of their life in addition to just at the time of arrival. In this study, information was collected from all the migrants the type and nature of problems they faced during their stay at place of destination. Table 2 listed ten major problems and categorized it according to the sex of the migrant. It is seen that 54.8 percent of males and 55.3 percent of female migrants reported to have remained unemployed at least once in their course of life at the place of destination. Overall percentage shows that 55.1 percent have faced the risk of being unemployed during an extended period of time. It is not surprising to find such larger proportion to get no employment at the place of destination since migrants (in Ethiopian context) are more likely to be illiterate or unskilled at the time of arrival. Also, the fact that many of them may lack support system and linkage at the place of destination, it is natural to expect that they become unemployed.

It is also reported that 21.4 percent of males and 27.2 female migrants faced the risk of contracting diseases once or more times during the course of their life as migrants in the current destination. The overall proportion shows that, about 23.4 percent of all migrants have encountered sickness at least once. The Chi-square analysis also revealed that there is some association between sex of the migrant and sickness encountered.

Whether a migrant has undergone labour exploitation (using the standard definition of ILO) at the place of destination or not, was also probed. It is seen in table 2 that 28.0 percent of male and 25.3 percent of female migrants have reported to undergone labor exploitation of one kind or the other. The overall percentage has also revealed that 26.8 percent of all migrants were exploited. Another problem, loosen family ties, was reported as one of the major problems faced by 58.3 percent of males and 58.7 percent of female, indicating that the case it nearly similar for both sexes.
The most striking gender differentials of migration impact were seen in reported problem of lack of food at the place of destination. More of male migrants ( 42.8 percent) than female migrants (31.5 percent) have reported to be suffering from serious food insecurity or insufficiency. The Chisquare result has also shows significant association between the sex of the migrant and vulnerability to food insecurity at the place of destination (P-value of 0.002).

The gender differential of reported sexual harassment is more for female migrant $(18.0 \%)$ than males (4.7\%). Overall, about 10.5 percent of migrants have reported to face sexual harassment of one kind or the other. The association between the sex of migrant and risk of harassment found to be significant at 0.001 ( $\mathrm{P}$-value of $0.000)$. Small proportion of both males and females reported to be vulnerable to crimes of some kind during the course of their stay at the place of destination. Such vulnerability, however, has not yield gender relationship.

Homelessness among migrants was reported to be one of the most serious reported problems. It is observed that 57.4 percent of males and 53.1 percent of females have reported to face homelessness. Further, 40.9 percent of males and 45.8 percent of females are reported to feel that they have experienced unequal opportunities in every aspect of life. It is also apparent to note that some respondents $(5.2 \%$ of males and 12.1 percent females) have reported to encounter repeated social crises such as steeetism and prostitution at the place of destination.

Contrary to the aforementioned problems faced by the migrants, information about the perceived success of migrating to the current destination was of a concern to this study. In this case, all the migrants were asked to indicate the positive impacts of their move to the current destination. Accordingly, more of the males $(60.0 \%)$ than the female respondents $(43.0 \%)$ perceived that they got better income opportunity compared to the situation at place of origin. Overall, 52.6 percent of all migrants felt that their income has been transforming to a better scale. The relationship between the two variables is also found to be significant at $0.001(\mathrm{P}$ - value of $0.000)$. Similarly, more of males $(57.2 \%)$ than female $(52.8 \%)$ reported to experience better education opportunities at the place of destination compared to place of origin. 
There is also gender differential in perceived job opportunities at the place of destination. In this regard, more male migrants $(58.1 \%$ than female migrant (40.4) feel to experience better job opportunities which is in line with the fact that urban life provides more jobs to males than females is well documented in many studies. The Chi-square result has also shown significant association between the two variables (P-value of 0.000 )

It is also evident from table 2 that quite larger number of the respondents $(59.0 \%)$ is reported to get satisfied with health facilities. More males $(60.0 \%)$ than females $(57.6 \%)$ experienced better health facilities. Another important finding of this study is that more of females $(54.5 \%)$ than males $(36.8 \%)$ reported that there is overall improvement in women's status. The Chi-square analysis has also exhibited this association (P-values of 0.000 ). About 82.6 percent of males and 84.0 percent of females migrants reported to have upgraded their skills after coming to the current destination.

The analysis of the key informants and focus group discussions also strengthened the aforementioned facts of gender differentials of migration impacts. The in-depth interview held with key informants from Women's Affairs Bureau, for instance, indicates that women are increasingly migrating to urban areas in search of job opportunities and better life. Some of the women are taking migration as the only way out from the marriage arrangement as a result of harmful traditional practices such as early marriage, abduction and unhealthy relationship in the family. In most cases the intended pull factor might not actually be reachable due to the poor skills and the overall negative attitudes of the community towards women. As a result, women who migrated from rural areas are forced to be engaged in activities such as housemaid, domestic works and other low paying and risky activities which ultimately expose them to various abuses such as sexual harassment, labor exploitation, rape, unwanted pregnancy, physical abuse and the like.

Once the migration impact at individual and household level is examined as discussed above, it is also important to briefly describe the possible impacts at community level. The fact that quantitative information was difficult to generate at the community level, the responses of the in-depth interview with the competent authori- ties in various government offices were used to describe the migration impacts at the community level. In all the discussions held with the concerned authorities, it was noted that the influx of people has increasingly alarming repercussions on the urban life. The impacts are reported to range from simple crowd to affecting the prospects of future growths of some of the towns.

Similarly, the in-depth interview held with officials in Gurage zone indicates that most of the urban centers of the zones are increasingly becoming attractive to rural exodus, but the quality of life in these urban areas is dwindling down due to increased pressures from the incoming migrants. Among others, the following problems were mentioned: growing number of street children, growing rate of the prostitution particularly after the new road being constructed, growing rate of crime, increasing rate of unemployment, increased prevalence of addiction to 'Chat', smoking and drinking, poverty has escalated as a result of sending children aboard. Families usually send children to the Middle East by taking debt from relatives. There are also cases in which the parents sale their house to cover the expense for processing the oversee payment for the middlemen and air fee.

\section{CONCLUSIONS AND POLICY IMPLICATIONS}

This survey is primarily devoted to examine the gender differentials in the impacts of migration in Southern Ethiopia. The input data for this study thus were collected from 12 kebeles of four major towns of the region (presumed to be the place of destinations). In order to collect the required information from the selected areas, two sets of interview schedule (questionnaire) and focus group discussion checklists were prepared as discussed in section 2 above. Analysis of the gender differentials in migration impacts were done by employing the Chi-square statistical techniques. On the basis of the information collected from the 821 urban respondents and taking into account all the methodological pitfalls of studying migration, this study has concluded that there are certain gender differentials in the impacts of migration at the place of destination. The Chi-Square analysis shows that male migrants are more prone to some of the socio-economic problems (such as unemployment) than their counterpart female migrants. Similarly, fe- 
male migrants are found to be more prone to some of urban problems (such as, lack of food, lack of adequate health service, homesickness, labor and sexual abuses and the like) than their counterpart migrants.

Also, it is understood that migration has a number of perceived successes which includes better job opportunities, education and status change (especially for women migrants. Although, migration in general causes complicated social problems in migrants' area of origin and destination in the region, the prevailing condition in some respect plays important roles as means of income generation schemes to attain food security at a household level. In rural areas where surplus labor is existent, migration reduce the burden on the use of available resources. Inline with this, rural households get some incomes in the form of remittance form permanent migrant family members and additional income from seasonal migrants. Moreover, this surplus labor can be utilized in urban areas to meet growing demand of labor in different investment fields. Hence, proper designing, planning and coordination of labour migration with stakeholders for creating good work environment and setting minimum wage rate for both seasonal as well as permanent migrants help to avoid labour exploitation and ensure household food self-sufficiency in the area of origin and destination.

\section{ACKNOWLEDGEMENT}

The authors would like to express their heart felt thanks to the regional office of population and the Hawassa University for all kinds of assistances given during the course of this study.

\section{REFERENCES}

Abate A 1989. Internal Migration and Urbanization in Ethiopia. Paper presented at the conference on Population Issues in Ethiopian's National Development, Addis Ababa, July 2002

Bauer TK, Haisken-DeNew JP, Schmidt CM 2004. International Labor Migration, Economic Growth and Labor Market: The Current State of Affairs. London.

Berhanu B, White M 1999. War, Famine and Female Migration in Ethiopia, 1960-89. Brown University, Population Studies and Training Center, Working paper No. 28.

CSA 2000. The population situation of Ethiopia. Addis Ababa: Country level Analytical Report.

ECA 2001. Africa's Population and Development Bulletin: Addis Ababa, Ethiopia: ECA.

Ezra M 1997. Demographic Responses to Ecological Degradation and Food Insecurity: Drought Prone Areas in Northern Ethiopia. Doctoral Dissertation Population Research Center. Amsterdam: University of Groningen, PDOD Publishers.

Ezra M 2001. Ecological degradation, Rural Poverty, and Migration in Ethiopia: A Contextual analysis (unpublished).

Khan Aliya H. 1997. Post Migration Investment in Education by Immigrants in the United States. The Quarterly Review of Economics and Finance, 37: Special Issue, 285-313.

Murphy M. 1996. The Dynamic Households as a Logical Concept and Its Use in Demography. European Journal of Population, 12(4): 363-381.

SNNPRG 2001. The Socioeconomic Profile of Southern Nations, Nationalities and Peoples Region. Awassa, Ethiopia: SNNPRG.

Mesfin Woldemariam 1986. Rural Vulnerability to Famine in Ethiopia: 1977-1985. London: Intermediate Technology Publications. 